\title{
Female genital mutilation/cutting (FGM/C) coding capacities in Swiss university hospitals using the International Classification of Diseases (ICD)
}

\author{
S. Cottler-Casanova ${ }^{1,2,3+}$, M. Horowicz ${ }^{4 \dagger}$, A. Gayet-Ageron ${ }^{5}$ and J. Abdulcadir ${ }^{1 *}$
}

\begin{abstract}
Background: The real prevalence and incidence of women living with or at risk of female genital mutilation/ cutting (FGM/C) is unknown in Switzerland and many parts of Europe, as there are no representative surveys similar to DHS or MICS for European countries. Indirect estimates are commonly used to estimate the number of women with FGM/C in high-income countries, but may not reflect the actual FGM/C prevalence among migrants. Direct measures may provide more accurate estimates that could guide policy- and clinical decision-making. Swiss hospital data may provide a sample of patients that can be used to describe the prevalence of FGM/C in Swiss hospitals. Our study assesses the number of inpatient women and girls in Swiss university hospitals from countries with high FGM/C prevalence, and of inpatients with a coded diagnosis of FGM/C.
\end{abstract}

Methods: We conducted an exploratory descriptive study in Switzerland to assess the number of women and girls admitted to Swiss university hospitals between 2016 and 2018 from 30 FGM/C practicing countries, as well as inpatients with a coded diagnosis of FGM/C using anonymized data. We calculated indirect estimates for inpatient women and girls living with or at risk of FGM/C and compared them with the number of inpatients with a coded diagnosis of FGM/C.

Results: 8720 women and girls from FGM/C practicing countries were admitted. 207 patients had a coded diagnosis of $\mathrm{FGM} / \mathrm{C}$, including 7 with a nationality outside the 30 targeted countries, corresponding to an overall prevalence of $2.3 \%(95 \% \mathrm{Cl}, 2.0-2.6)$. The number of FGM/C cases by hospital was significantly different across years $(P<0.001)$, with a higher proportion of cases collected in Geneva, Switzerland.

Conclusions: The comparison between indirect estimates of inpatients with or at risk of FGM/C and the low number of FGM/C cases coded, suggests low recording and coding capacities of FGM/C.

Tweetable abstract: The capacity of coding primary and secondary diagnosis of FGM/C in Swiss university hospitals seems low.

Protocol number: 2018-01851: SwissEthics Committee, Canton of Geneva, Switzerland.

\footnotetext{
* Correspondence: jasmine.abdulcadir@hcuge.ch

${ }^{\dagger}$ S. Cottler-Casanova and M. Horowicz contributed equally to this work. 'Division of Gynaecology, Department of the Woman, the Child and the Adolescent, Geneva University Hospitals, 30 Bld de la Cluse, 1211 Geneva, Switzerland

Full list of author information is available at the end of the article
}

(c) The Author(s). 2021 Open Access This article is licensed under a Creative Commons Attribution 4.0 International License, which permits use, sharing, adaptation, distribution and reproduction in any medium or format, as long as you give appropriate credit to the original author(s) and the source, provide a link to the Creative Commons licence, and indicate if changes were made. The images or other third party material in this article are included in the article's Creative Commons licence, unless indicated otherwise in a credit line to the material. If material is not included in the article's Creative Commons licence and your intended use is not permitted by statutory regulation or exceeds the permitted use, you will need to obtain permission directly from the copyright holder. To view a copy of this licence, visit http://creativecommons.org/licenses/by/4.0/ The Creative Commons Public Domain Dedication waiver (http://creativecommons.org/publicdomain/zero/1.0/) applies to the data made available in this article, unless otherwise stated in a credit line to the data. 
Keywords: Female genital mutilation, Female genital cutting, Female genital mutilation/cutting, Indirect estimates, Prevalence, Coding, International classification of diseases, ICD, Switzerland

\section{Introduction}

Female genital mutilation/cutting (FGM/C) is the partial or total removal of the external female genitalia for nonmedical reasons [1]. The World Health Organization describes four FGM/C types [Table 1]. Approximately 200 million women and girls have undergone the practice according to UNICEF [2]. The Demographic Health Survey (DHS) developed by ICF International or the Multiple Indicator Cluster Surveys (MICS) directed by UNICEF, conducted in 27 African and three Asian countries practicing $\mathrm{FGM} / \mathrm{C}$ provide $\mathrm{FGM} / \mathrm{C}$ prevalence estimates based on nationally representative data [4]. These estimates do not include women and girls living with FGM/C who emigrated from FGM/C practicing countries [4]. In the European Union (EU), there were an estimated 578,068 women and girls living with FGM/C in 2011 [5], and 21,706 in Switzerland in 2018 [6] based on indirect measures, where the number of migrant women from a FGM/C practicing country is multiplied by the FGM/C prevalence rate from the same country. The European Institute for Gender Equality estimated the number of migrant girls (0-18) from FGM/C practicing countries at risk of FGM/C as 44,106 in France (2014); 18,339 in Italy (2016); 6122 in Belgium (2016), and a few hundred in Greece, Cyprus, Malta, Ireland, Portugal and Sweden [7, 8].

Indirect estimation is a systematic and affordable method for estimating the number of women with $\mathrm{FGM} / \mathrm{C}$ in high-income countries, in the assumption that the prevalence of FGM/C among migrants does not significantly differ from prevalence among non-migrants [9-11]. However, due to several reasons, including cultural change and varying socioeconomic, and ethnic origins of migrants, it may not reflect the actual FGM/C prevalence in migrants' country of residence or community $[12,13]$. The real prevalence and incidence of FGM/ $\mathrm{C}$ and the number of minors at risk remains unknown in many countries.

Direct measures may provide more accurate estimates that could guide policy- and clinical decision-making. Surveying samples of migrants to estimate FGM/C prevalence also has limitations, as they might not know whether they experienced FGM/C or be unaware of the type [14]. Swiss hospital data may provide a sample of patients that can be used to describe the prevalence of FGM/C in Swiss hospitals. Furthermore, hospital data represents an opportunity to study access and quality of care for patients who underwent $\mathrm{FGM} / \mathrm{C}$, providing guidance for health interventions [15-17].

No data are available on the number of women and girls with FGM/C in Swiss hospitals. No accurate information is available on Swiss healthcare professionals' capacities to record FGM/C and deal with its complications and prevention. Weak capacities in diagnosis, recording and coding represent the major obstacle to studying hospital data on FGM/C. Studies from Switzerland and other high- and low-income countries, among midwives, gynecologists and obstetricians,

Table 1 Classification of FGM/C according to WHO [3]. When WHO refers to "glans of the clitoris", part of the body of the clitoris can also be affected

\begin{tabular}{|c|c|}
\hline Type I & $\begin{array}{l}\text { Partial or total removal of the clitoral glans (the external and visible part of the clitoris, which is a sensitive part of the female } \\
\text { genitals, with the function of providing sexual pleasure to the woman), and/or the prepuce/clitoral hood (the fold of skin } \\
\text { surrounding the clitoral glans). }\end{array}$ \\
\hline Type la & Removal of the prepuce/clitoral hood only \\
\hline Type lb & Removal of the clitoral glans with the prepuce/clitoral hood \\
\hline Type II & Partial or total removal of the clitoral glans and the labia minora, with or without removal of the labia majora. \\
\hline Type Ila & Removal of the labia minora only \\
\hline Type Ilb & Partial or total removal of the glans of the clitoris and the labia minora \\
\hline Type Ilc & Partial or total removal of the glans of the clitoris, the labia minora and the labia majora \\
\hline $\begin{array}{l}\text { Type III } \\
\text { (Infibulation) }\end{array}$ & $\begin{array}{l}\text { Narrowing of the vaginal opening with the creation of a covering seal. The seal is formed by cutting and repositioning the } \\
\text { labia minora, or labia majora. The covering of the vaginal opening is done with or without removal of the clitoral prepuce/ } \\
\text { clitoral hood and glans. }\end{array}$ \\
\hline Type IIla & Removal and apposition of the labia minora \\
\hline Type IIIb & Removal and apposition of the labia majora \\
\hline Type IV & $\begin{array}{l}\text { All other harmful procedures to the female genitalia for non-medical purposes, for example, pricking, piercing, incising, scraping } \\
\text { and cauterization. }\end{array}$ \\
\hline
\end{tabular}


general and travel medicine practitioners have shown difficulties in screening, diagnosing, classifying and recording FGM/C [18-23]. Pediatricians also lack training on FGM/C and rarely perform external genital examinations $[24,25]$.

In this manuscript, we aim to:

(1) Assess the number of women and girls from FGM/ $C$ practicing countries admitted to Swiss university hospitals.

(2) Estimate, using indirect measures, the potential number of inpatients who are possibly living with $\mathrm{FGM} / \mathrm{C}$.

(3) Measure the number of inpatients with a coded primary or secondary diagnosis of FGM/C. The comparison between indirect estimates of inpatients with FGM/C and the number of FGM/C cases coded in the same hospitals, can inform the diagnostic, recording and coding capacities of FGM/C in Swiss university hospitals.

\section{Methods}

This cross-sectional study was part of a larger research study approved in December, 2018: protocol number 2018-01851 by the Swiss Ethics Committees (SwissEthics) and conducted according to the protocol, the Swiss legal requirements, and the World Medical Association Declaration of Helsinki. An exemption of informed consent was granted by the state of Geneva Swiss Ethics committee for the use of anonymized data extracted from the university hospitals databases. We first calculated the indirect estimates of women and girls living with FGM/C in Switzerland between 2010 and 2018 [6]. We used a similar methodology to Yoder and Van Baelen [5, 26], applying the most recent FGM/C DHS and MICS prevalence figures for each year (for girls and women aged 15-49) from $\mathrm{FGM} / \mathrm{C}$ practicing countries to the number of migrant women and girls living in Switzerland. We applied the total country prevalence estimates of women aged 15-49 to all migrant women and girls living in Switzerland from the same countries. We also conducted a separate analysis for girls aged $0-14$, where we applied the prevalence estimates of girls $0-14$ to all migrant girls $0-14$ living in Switzerland from the same countries. Where no prevalence estimates for girls $0-14$ were available, we applied the prevalence estimates for girls 15-19. Full details are available in another paper [6] [Tables S1 \& S2].

Secondly, in February 2019, we asked the five Swiss university hospitals to provide anonymized data for all inpatient women and girls with a nationality from the 30 FGM/C practicing countries [Table 2], and for all inpatients with a diagnosis of FGM/C between 2016 and 2018 [Table 3]. Swiss hospital data only provided information on patient's nationality, and we therefore used this as a proxy for country of origin, discussed in limitations. In Swiss hospitals, healthcare professionals record diagnosis in patients' electronic medical charts, and professional coders code this information with the tenth edition of the International Classification of Diseases (ICD) [27]. We received data from the University Hospitals of Geneva (HUG), Lausanne (CHUV), Bern (Inselspital) and Zurich (USZ). The University Hospital of Basel did not participate due to logistical difficulties in data provision. The implication is discussed in the conclusion. Analyses were carried out using STATA version 15.

The participating hospitals provided data on all inpatient women and girls from the 30 targeted countries and all primary and secondary diagnoses of FGM/C coded between January 1, 2016 and December 31, 2018. Therefore, we estimate indirect prevalence of FGM/C in Swiss hospitals as the proportion of the total number of FGM/C cases recorded on the total number of women and girls from the targeted countries in four Swiss university hospitals between 2016 and 2018. Using the country prevalence estimates of FGM/C among women and girls with a nationality from FGM/C practicing countries in 2016, 2017, and 2018, we then multiplied this prevalence estimates to the total number of inpatient women and girls registered with the same nationality in the hospital database during the same period and obtained an indirect estimation of the number of inpatients with FGM/C in our Swiss hospitals [Table 5]. Inpatients with an $\mathrm{FGM} / \mathrm{C}$ diagnosis that had a nationality from other countries than the ones targeted were not considered in this estimation.

We provided descriptive statistics with mean, \pm standard deviation (SD), and median for continuous variables; number and proportions by categories for qualitative variables. We compared all categorical variables by year and FGM/C type by region (West Africa vs. East Africa) using Chi-2 or Fischer's exact tests. We compared mean ages by year using non-parametric Kruskal-Wallis test. We estimated FGM/C prevalence within the Swiss university hospital population between 2016 and 2018 and their 95\% confidence intervals (95\%CIs) using the binomial exact method (Clopper-Pearson method).

\section{Results}

8720 women and girls from countries with high FGM/C prevalence were admitted between 2016 and 2018: 4388 in Bern, 2372 in Geneva, 1218 in Lausanne and 742 in Zurich [Table 2]. Most of them came from Eritrea (31.0\%), followed by Somalia in Geneva, Zurich and Bern (11.6\%), and Cameroon in Lausanne (9.7\%).

207 inpatient women and girls had a coded diagnosis of FGM/C [Table 3]. The number of FGM/C cases by 
Table 2 Total number of women and girls in Swiss university hospitals between 2016 and 2018 from 30 FGM/C practicing countries

\begin{tabular}{|c|c|c|c|c|c|}
\hline Country of origin & ZürichTotal & Lausanne Total & $\begin{array}{l}\text { Geneva } \\
\text { Total }\end{array}$ & $\begin{array}{l}\text { Bern } \\
\text { Total }\end{array}$ & Total \\
\hline Benin & 2 & 12 & 18 & 5 & 37 \\
\hline Burkina Faso & 3 & 12 & 54 & 21 & 90 \\
\hline Cameroon & 52 & 256 & 261 & 274 & 843 \\
\hline Central African Republic & 1 & 1 & 3 & 3 & 8 \\
\hline Chad & 2 & 1 & 2 & 13 & 18 \\
\hline Djibouti & 0 & 4 & 3 & 0 & 7 \\
\hline Egypt & 20 & 15 & 107 & 101 & 243 \\
\hline Eritrea & 167 & 295 & 362 & 1881 & 2705 \\
\hline Ethiopia & 59 & 100 & 123 & 287 & 579 \\
\hline Gambia & 7 & 3 & 8 & 16 & 34 \\
\hline Ghana & 42 & 6 & 53 & 79 & 180 \\
\hline Guinea & 8 & 41 & 101 & 31 & 181 \\
\hline Guinea-Bissau & 0 & 14 & 9 & 2 & 25 \\
\hline Indonesia & 20 & 12 & 33 & 64 & 129 \\
\hline Iraq & 66 & 74 & 164 & 481 & 785 \\
\hline Ivory Coast & 41 & 47 & 146 & 72 & 306 \\
\hline Kenya & 41 & 6 & 63 & 125 & 235 \\
\hline Liberia & 2 & 3 & 5 & 5 & 15 \\
\hline Mali & 2 & 1 & 32 & 6 & 41 \\
\hline Mauritania & 0 & 1 & 27 & 1 & 29 \\
\hline Niger & 0 & 4 & 23 & 11 & 38 \\
\hline Nigeria & 42 & 36 & 88 & 169 & 335 \\
\hline Senegal & 5 & 42 & 195 & 29 & 271 \\
\hline Sierra Leone & 4 & 3 & 20 & 23 & 50 \\
\hline Somalia & 101 & 157 & 233 & 523 & 1014 \\
\hline Sudan and South Sudan & 30 & 2 & 79 & 63 & 174 \\
\hline Tanzania & 7 & 1 & 33 & 13 & 54 \\
\hline Togo & 3 & 61 & 78 & 36 & 178 \\
\hline Uganda & 3 & 1 & 28 & 24 & 56 \\
\hline Yemen & 12 & 7 & 21 & 20 & 60 \\
\hline Grand Total & 742 & 1218 & 2372 & 4388 & 8720 \\
\hline
\end{tabular}

center significantly changed over the years $(P<0.001)$ with more cases in Geneva overall, and it was significantly different by department $(P<0.001)$ with most cases coded in obstetrics. Patients with an FGM/C diagnosis mostly originated from Eritrea $(n=85)$ and Somalia $(n=54)$.

The FGM/C type differed significantly depending on the region of origin $(P=0.004)$ : types II and III were significantly more frequent among patients from West Africa and from East Africa, respectively [Table S3].

For all years combined, the calculated FGM/C prevalence was $2.29 \%$ (95\%CI: 1.98-2.62). We excluded seven patients from CHUV who had a coded diagnosis of FGM/C and were registered as Swiss $(\mathrm{n}=4)$, Ecuadorian $(n=1)$, Turkish $(\mathrm{n}=1)$ and French $(\mathrm{n}=1)$. Thus, outside the 30 targeted countries. FGM/C prevalence significantly increased over time in participating centers: $1.24 \%$ in 2016, $2.32 \%$ in 2017 , and $3.32 \%$ in $2018(P<0.001)$.

$\mathrm{FGM} / \mathrm{C}$ prevalence in Swiss hospitals was 3.53\% among inpatients from countries with the highest FGM/ $C$ prevalence $(\geq 81 \%)$, and thus higher than among inpatients from countries with lower FGM/C prevalence $(P<0.001)$. [Table S3]. FGM/C prevalence was significantly higher in women from East Africa $(P<0.001)$. 
Table 3 Description of patients with a FGM/C $(n=207)$ as main or secondary diagnosis between 2016 and 2018 in one of four Swiss university hospitals (Geneva, Lausanne, Bern and Zurich)

\begin{tabular}{|c|c|c|c|c|}
\hline Variables & $\begin{array}{l}2016 \\
(n=42)\end{array}$ & $\begin{array}{l}2017 \\
(n=69)\end{array}$ & $\begin{array}{l}2018 \\
(n=96)\end{array}$ & $P$ value \\
\hline Center, n (\%) & & & & $<0.001^{\mathrm{a}}$ \\
\hline Geneva & $20(47.6)$ & $24(34.8)$ & $67(69.8)$ & \\
\hline Lausanne & $13(31.0)$ & $10(14.5)$ & 19 (19.8) & \\
\hline Bern & $3(7.1)$ & $23(33.3)$ & $6(6.3)$ & \\
\hline Zurich & $6(14.3)$ & $12(17.4)$ & $4(4.2)$ & \\
\hline Country of origin, n (\%) & & & & $0.097^{\mathrm{a}}$ \\
\hline Benin & $0(0)$ & $0(0)$ & $1(1.0)$ & \\
\hline Burkina Faso & $1(2.4)$ & $2(2.9)$ & $0(0)$ & \\
\hline Cameroon & $1(2.4)$ & $0(0)$ & $0(0)$ & \\
\hline Egypt & $0(0)$ & $0(0)$ & $5(5.2)$ & \\
\hline Eritrea & $12(28.6)$ & $37(53.6)$ & $36(37.5)$ & \\
\hline Ethiopia & $2(4.8)$ & $3(4.4)$ & $2(2.1)$ & \\
\hline Guinea & $0(0)$ & $0(0)$ & $6(6.2)$ & \\
\hline Guinea-Bissau & $0(0)$ & $0(0)$ & $2(2.1)$ & \\
\hline Ivory Coast & $1(2.4)$ & $1(1.5)$ & $1(1.0)$ & \\
\hline Mali & $0(0)$ & $0(0)$ & $1(1.0)$ & \\
\hline Mauritania & $0(0)$ & $0(0)$ & $1(1.0)$ & \\
\hline Nigeria & $1(2.4)$ & $1(1.5)$ & $3(3.1)$ & \\
\hline Senegal & $0(0)$ & $0(0)$ & $3(3.1)$ & \\
\hline Somalia & $14(33.3)$ & $18(26.1)$ & $22(22.9)$ & \\
\hline Sudan and South Sudan & $1(2.4)$ & $1(1.5)$ & $3(3.1)$ & \\
\hline Unknown or other & $9(21.4)$ & $6(8.7)$ & $10(10.4)$ & \\
\hline Service, n (\%) & & & & $<0.001^{\mathrm{a}}$ \\
\hline Gynecology & $13(31.0)$ & $12(17.4)$ & $9(9.4)$ & \\
\hline Gynecology or Obstetrics* & $1(2.4)$ & $23(33.3)$ & $6(6.3)$ & \\
\hline Obstetrics & $23(54.8)$ & $33(47.8)$ & 79 (82.3) & \\
\hline Others & $5(11.9)$ & $1(1.5)$ & $2(2.1)$ & \\
\hline Mean age at first visit ( $\pm \mathrm{SD}$, median) & $30.7( \pm 12.0,27)$ & $27.7( \pm 6.1,27.4)$ & $29.8( \pm 6.7,30)$ & $0.162^{b}$ \\
\hline FGM/C type, n (\%) & & & & $0.116^{b}$ \\
\hline Type I & $3(7.1)$ & $13(18.8)$ & $10(10.4)$ & \\
\hline Type II & $8(19.1)$ & $16(23.2)$ & $33(34.4)$ & \\
\hline Type III & $21(50.0)$ & $33(47.8)$ & 39 (40.6) & \\
\hline Type IV & $0(0)$ & $1(1.5)$ & $2(2.1)$ & \\
\hline Unspecified or other & $10(23.8)$ & $6(8.7)$ & $12(12.5)$ & \\
\hline \multicolumn{5}{|l|}{ FGM/C type, n (\%) } \\
\hline N90.80 (Female genital mutilation, type unspecified) & $3(7.1)$ & $0(0)$ & $0(0)$ & \\
\hline N90.81 (FGM, Type I) & $3(7.1)$ & $0(0)$ & $0(0)$ & \\
\hline N90.82 (FGM, Type II) & $8(19.1)$ & $0(0)$ & $0(0)$ & \\
\hline N90.83 (FGM, Type III) & $21(50.0)$ & $0(0)$ & $0(0)$ & \\
\hline N90.88 Other specified non-inflammatory diseases of the vulva and perineum & $7(16.7)$ & $0(0)$ & $0(0)$ & \\
\hline Z91.70 Personal history of female genital mutilation, type unspecified & $0(0)$ & $6(8.7)$ & $12(12.5)$ & \\
\hline Z91.71 (FGM, Type I) & $0(0)$ & $13(18.8)$ & $10(10.4)$ & \\
\hline Z91.72 (FGM, Type II) & $0(0)$ & $16(23.2)$ & $33(34.4)$ & \\
\hline
\end{tabular}


Table 3 Description of patients with a FGM/C $(n=207)$ as main or secondary diagnosis between 2016 and 2018 in one of four Swiss university hospitals (Geneva, Lausanne, Bern and Zurich) (Continued)

\begin{tabular}{llll}
\hline Variables & $\begin{array}{l}\mathbf{2 0 1 6} \\
(\boldsymbol{n}=\mathbf{4 2})\end{array}$ & $\begin{array}{l}\mathbf{2 0 1 7} \\
(\boldsymbol{n}=\mathbf{6 9 )}\end{array}$ & $\begin{array}{l}\mathbf{2 0 1 8} \\
(\boldsymbol{n}=\mathbf{9 6})\end{array}$ \\
\hline Z91.73 (FGM, Type III) & $0(0)$ & $33(47.8$ & $39(40.6)$ \\
Z91.74 (FGM, Type IV) & $0(0)$ & $1(1.5)$ & $2(2.1)$ \\
\hline
\end{tabular}

${ }^{\mathrm{a}}$ Fischer's exact test; ${ }^{\mathrm{b}}$ Kruskal-Wallis nonparametric test

* Bern's datasets did not differentiate gynecological from obstetrical units

We applied the FGM/C prevalence among inpatients from each at-risk country separately [Table 5] and indirectly estimated the number of inpatients who could have undergone or be at risk of undergoing FGM/C: 1648 in 2016, 1671 in 2017, and 1628 in $2018(n=4947)$.

FGM/C prevalence was lower among minors $(0.66 \%)$, compared to women above 18 years old $(2.46 \%)(P<$ 0.001 ) [Tables 4 and 5]. FGM/C prevalence also varied by hospital department, with higher prevalence among inpatients in gynecology and obstetrics $(P<0.001)$. It also varied among women and girls from at-risk countries. It was higher in Geneva, similar in Lausanne and Zürich, and lower in Bern $(P<0.001)$. Prevalence was higher in institutions featuring regular educational programmes about $\mathrm{FGM} / \mathrm{C}$ and/or a clinic or referral physician for FGM/C.

\section{Discussion}

\section{Main findings}

Our findings show that only 207 patients $(2.29 \%)$ have a coded FGM/C diagnosis, with an increase between 2016 and 2018. There is a drastic difference between FGM/C cases coded in Swiss university hospitals $(n=207)$ and the possible number of women and girls with FGM/C in these hospitals based on our indirect estimates $(n=$ 4947). Our results suggest that FGM/C is not accurately diagnosed, recorded and/or coded in Swiss university hospitals. Moreover, most women and girls came from Eritrea and Somalia, where FGM/C prevalence exceeds $80 \%$, and where type III is frequent, the latter type being easier to identify, and associated with more long-term complications [1]. Infibulation was indeed the most frequent type among inpatients from East Africa.

Seven inpatients with an FGM/C code did not have the nationality of a country where the practice is usually performed. The nationality recorded or FGM/C coding might be incorrect. Alternatively, these women come from FGM/C practicing countries but possess another nationality, and underwent FGM/C before migrating, or afterwards while visiting their country of origin. In such case, and if coding is accurate, monitoring FGM/C

Table 4 Prevalence of FGM/C by age, hospital department, center, and educational programme attendance $(n=200 \mathrm{FGM} / \mathrm{C})$

\begin{tabular}{|c|c|c|c|c|}
\hline Variables & Number of cases, $n$ & $\mathrm{~N}$ & Prevalence, \% (95\%Cl) & $P$ value \\
\hline Category of age, n (\%) & & & & $0.001^{2}$ \\
\hline$<18$ years & 5 & 757 & $0.66(0.21-1.53)$ & \\
\hline$>=18$ years & 195 & 7936 & $2.46(2.13-2.82)$ & \\
\hline Hospital department, n (\%) & & & & $<0.001^{\mathrm{a}}$ \\
\hline Gynecology \& obstetrics & 195 & 4163 & $4.68(4.06-5.37)$ & \\
\hline Surgery & 2 & 1266 & $0.16(0.019-0.57)$ & \\
\hline Medical department & 1 & 2362 & $0.042(0.0011-0.24)$ & \\
\hline Emergency & 0 & 573 & $0(0-0.64)$ & \\
\hline Pediatrics & 2 & 374 & $0.53(0.065-1.92)$ & \\
\hline Center, n (\%) & & & & $<0.001^{\mathrm{b}}$ \\
\hline Geneva & 111 & 2390 & $4.64(3.84-5.57)$ & $<0.001^{\mathrm{b}}$ \\
\hline Lausanne & 35 & 1218 & $2.87(2.01-3.97)$ & \\
\hline Bern & 32 & 4388 & $0.73(0.50-1.03)$ & \\
\hline Zürich & 22 & 742 & $2.96(1.87-4.45)$ & \\
\hline \multicolumn{5}{|c|}{ Educational programme organised, $\mathrm{n}(\%)$} \\
\hline Yes (Geneva, Lausanne) & 146 & 3608 & $4.05(3.43-4.74)$ & \\
\hline No or unknown (Bern, Zürich) & 54 & 5130 & $1.05(0.79-1.37)$ & \\
\hline
\end{tabular}

${ }^{\mathrm{a}}$ Fischer's exact test, ${ }^{\mathrm{b}} \mathrm{Chi}-2$ test 


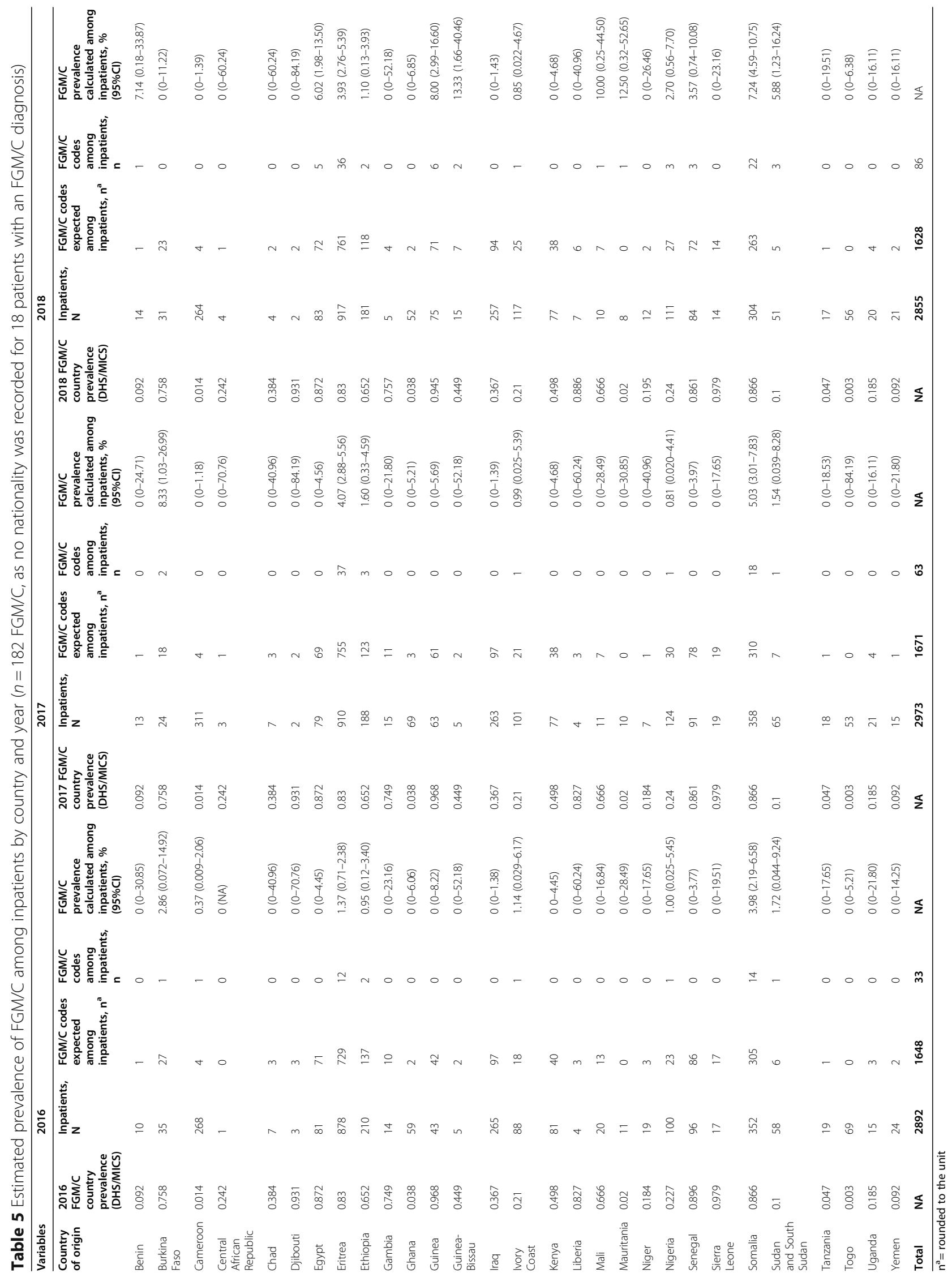


prevalence with ICD codes might give more reliable results than indirect estimates and overcome the issue of nationality and ethnicity.

Coding was significantly higher in gynecology and obstetrics compared to other departments. Obstetricians and gynecologists routinely examine the external genitalia and might be more trained to recognize FGM/C. Furthermore, our results suggest that pregnancy and delivery are critical times for diagnosing FGM/C, because it was significantly more coded in obstetrics than in gynecology. Only two girls in pediatrics and two women in urology were coded with FGM/C.

The prevalence of FGM/C codes in minors $(0.66 \%)$ was significantly lower than in adult women $(2.46 \%)$. Belonging to a new generation of immigrants, length of stay, and migration in a country where FGM/C is illegal could explain why it is less frequent among minors [7, 8, 12]. However, insufficient screening and routine genital examinations among pediatricians, or absent documentation can also explain the low numbers [23]. A specific code for "risk of FGM/C" might facilitate screening and prevention [17].

Longstanding training and protocols about $\mathrm{FGM} / \mathrm{C}$ in Geneva and Lausanne could explain why FGM/C prevalence in these hospitals was higher than in Bern, even though Bern numbered more patients from FGM/C practicing countries. At HUG for instance, a retrospective review of the medical files of patients who attended the FGM/C outpatient clinic between 2010 and 2012 revealed missed and misclassification of $\mathrm{FGM} / \mathrm{C}$ in more than one-third of cases [18]. Therefore, the obstetric and gynecologic divisions implemented several interventions: updating the protocols for the care of women and girls with FGM/C, learning tools with drawings, pictures and videos [28], workshops for midwives, and simulation programmes on defibulation. Since 2010, workshops were also organized in pediatrics, travel medicine, HIV clinic, infectious disease, and primary care. In 2017, the HUG hosted an International expert symposium on the care of women and girls with FGM/C and on prevention [29]. In 2012, the HUG's division of gynecology introduced an FGM/C checkbox in electronic medical forms to record FGM/C and its type. An update in February 2018 [Figs. 1 \& 2] added the description of FGM/C types and subtypes in gynecology and obstetrics. This may have facilitated screening and recording, explaining why FGM/C codes almost tripled between 2017 and 2018 .

According to a survey run by the Swiss Network against Female Circumcision in 2017 (unpublished, data obtained from the authors), FGM/C was taught at the medical faculties of the Universities of Geneva, Lausanne and Fribourg but not in Bern, whose university hospital admitted 4388 women and girls from FGM/C practicing countries between 2016 and 2018. This might partially explain the higher FGM/C prevalence in Geneva and Lausanne. Zürich's medical faculty did not reply to this survey.

\section{Strengths and limitations}

One strength of the study was the use of ICD-10 codes for estimating $\mathrm{FGM} / \mathrm{C}$ prevalence, making it easily reproducible to allow comparison of data over time, and after specific interventions [17].

The main weakness is that we could only collect data of patients, for whom FGM/C had been coded, and undercoding is evident. FGM/C is probably not recorded/coded when the reason for hospitalization and FGM/C are not related. However, even when they are related, FGM/C recording/coding is probably missing:

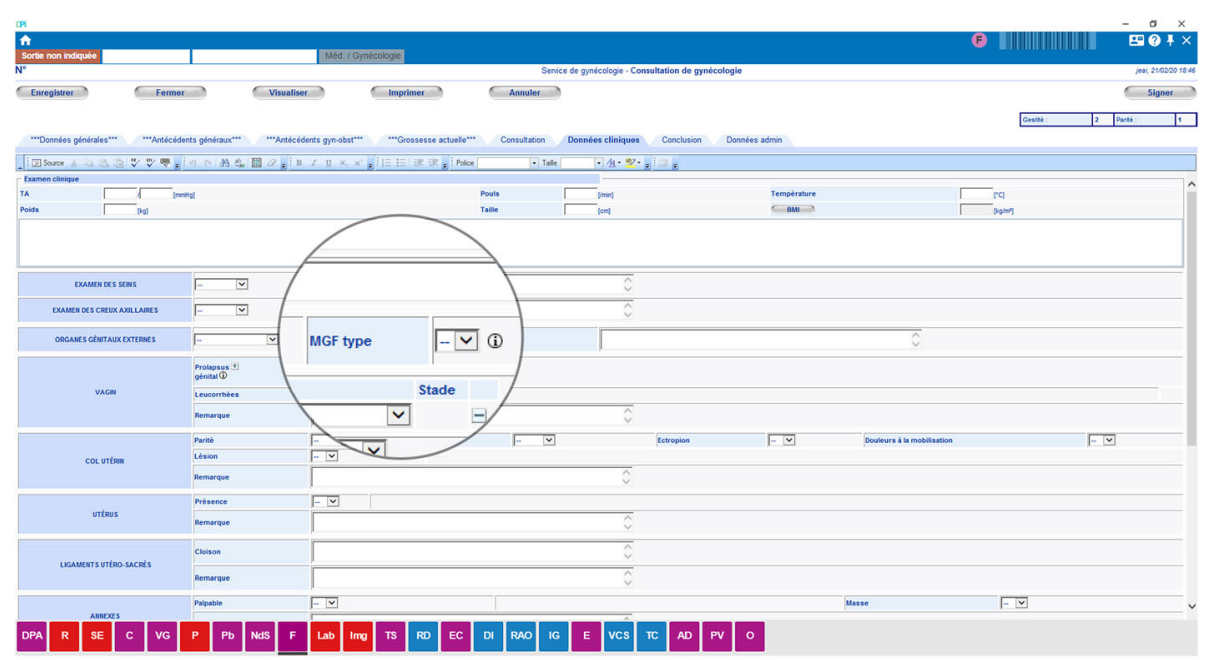

Fig. $1 \mathrm{FGM} / \mathrm{C}$ checkbox in the gynecological electronic medical chart 


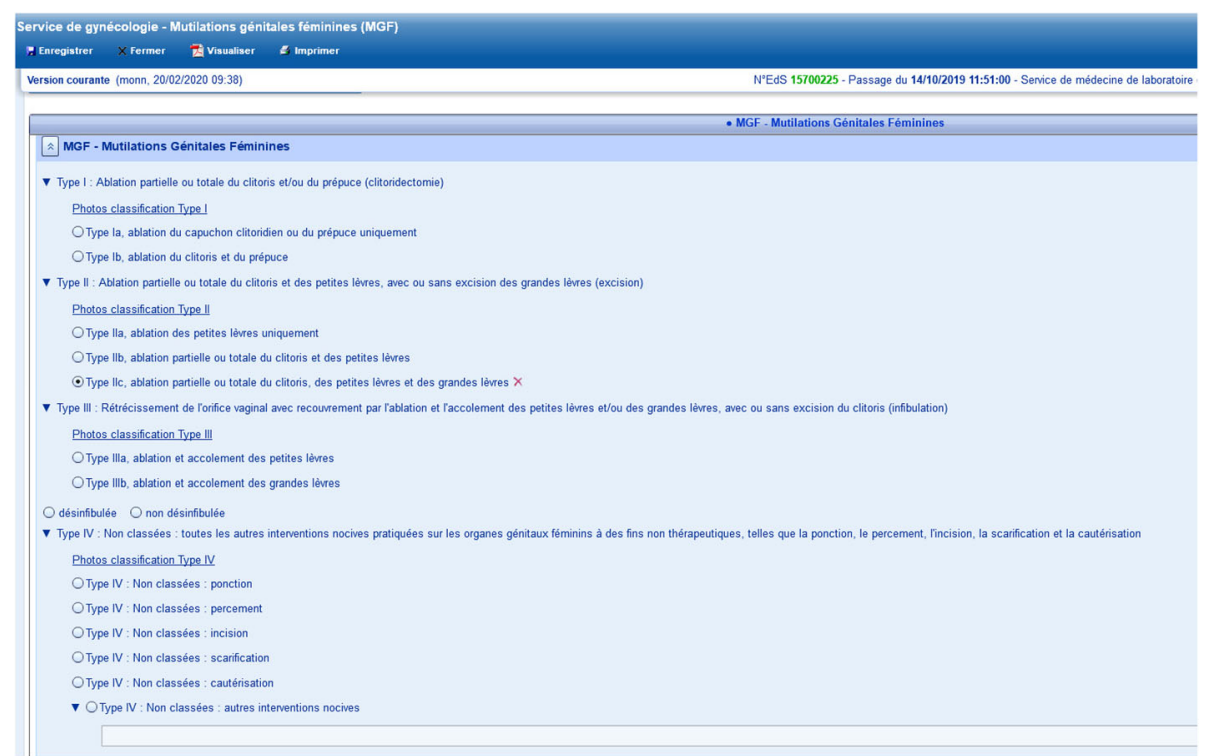

Fig. 2 FGM/C type and description in the gynecological electronic medical chart

the calculated prevalence of FGM/C among 4163 inpatient women in obstetrics and gynecology is only $4.68 \%$.

We included inpatients registered with the nationality from one of $30 \mathrm{FGM} / \mathrm{C}$ practicing countries, irrespective of whether they were first- or second- (or third-) generation migrants. This may exclude women who might originally come from one of these countries but have now a different nationality.

We did not have the information regarding the age of all inpatient women in the anonymized data. However, the aim of our study was not to assess the prevalence by 5 -year age groupings as is often done in high FGM/C prevalence countries to assess the evolution of the practice. Even though FGM/C is age-dependent, it is generally performed before menarche [30] and before migrating [31, 32]. Furthermore, in Swiss university hospitals, inpatients that are less than 16 years old are generally hospitalized in the pediatric division. We can hypothesize that all inpatients except for those from pediatric departments are more than 16 years old, and are therefore likely over the age of cutting. Future research reproducing our methodology might analyze the age of the women and girls included. We can hypothesize that a considerable number of inpatient women in Swiss university hospitals are mainly women of childbearing age as they were mostly attended in gynecology or obstetrics units.

We limited our study to four Swiss university hospitals. Basel's University Hospital could not provide the data requested, but we hypothesize that we would have found equally low FGM/C prevalence. We did not study regions without university hospitals, such as Tessin, on the Italian border, where hospitals could admit migrant women and girls with or at risk of FGM/C [9].

We included hospitalized patients only. It would be interesting to analyze data of outpatient women and girls in pediatrics, travel medicine, infectious disease, primary care services, and migrants' physical and mental health programmes.

\section{Interpretation}

The number of inpatients with an FGM/C diagnosis out of all women and girls potentially living with FGM/C is low in all hospitals and specialties, including gynecology and obstetrics. We believe that FGM/C coding indirectly reflects awareness of the phenomenon. If FGM/C is not recognized or discussed, women and girls living with FGM/C cannot access specific care, health and legal information and prevention.

Our study suggests that training healthcare professionals and medical students increases the number of patients coded with FGM/C. A study conducted in Belgium showed that more patients were coded with FGM/C after delivering information on FGM/C and its management [33]. The introduction of an FGM/C checkbox in electronic medical charts also seems to facilitate the diagnosis. Similar use of electronic tools facilitated identification of intimate partner violence, together with routine protocols on appropriate screening and counseling [34]. Since November 2019, at HUG, the FGM/C checkbox is linked to a standardized form where physicians, nurses and midwives can record the type, subtype and complications identified, and access an illustrated description from a learning tool for each item [28]. 


\section{Conclusion}

The present study shows that assessing FGM/C coding through ICD-10 is feasible but FGM/C coding capacities among inpatients in Swiss university hospitals are low.

Future policies should include training on appropriate screening, diagnosis, management and referral in case of FGM/C. Training should be organized in different specialties such as urology, obstetrics and gynecology, infectious diseases, general practice, pediatrics and psychiatry [35], and stress the importance of recording and coding. Certified interpreters and coders should also receive training. Finally, professionals in obstetrics, pediatrics, primary care, and travel medicine should be able to identify children at risk and discuss prevention, national laws on FGM/C and child's rights [22-25, 36]. Sensitizing and teaching about $\mathrm{FGM} / \mathrm{C}$ in existing pre-graduate classes, such as anatomy, gynecology and obstetrics, urology, infectious disease, pediatrics, psychiatry and primary care could improve standard training.

Our next step is to assess knowledge, attitudes and practice of healthcare professionals in the same hospitals to tailor training programmes and tools that can improve screening, prevention, diagnosis and management of FGM/C. We will also analyze our data according to the belonging of the included institutions to Swiss Hospitals for equity, a network aiming at improving healthcare access for underprivileged groups, regardless of their origin, language and socioeconomic situation. Routine availability of certified interpreters, like in Geneva and Lausanne, might facilitate diagnosis, recording and coding of FGM/C.

\section{Supplementary Information}

The online version contains supplementary material available at https://doi. org/10.1186/s12889-021-11160-6.

Additional file 1.

\section{Acknowledgments}

Monique Lamuela Naulin (Department of the Woman, the Child and the Adolescent) who provided figures and information on HUG medical records. Marisa Birri (Swiss Network Against Female Genital Mutilation) who provided information on pre-grade curricula and FGM/C.

\section{Authors' contributions}

JA designed and directed the project. SCC collected the data, together with JA and MH. SCC and AGA did the data analysis. MH, SCC and JA wrote the manuscript in collaboration with AGA. All the authors reviewed and approved the manuscript.

\section{Funding}

This study was funded by the Swiss Network Against Female Genital Cutting, Caritas Switzerland, and the Swiss Federal Office of Public Health.

\section{Availability of data and materials}

The datasets used and/or analysed during the current study available from the corresponding author on reasonable request.

\section{Declarations}

\section{Details of ethics approval}

This cross-sectional study was part of a larger research study approved in December, 2018: protocol number 2018-01851 by the Swiss Ethics Committee (SwissEthics) and conducted according to the protocol, the Swiss legal requirements, the World Medical Association Declaration of Helsinki. An exemption of informed consent was granted by the state of Geneva Swiss Ethics committee for the use of anonymized data extracted from the university hospitals databases.

\section{Consent for publication}

All authors have approved the manuscript for submission.

\section{Competing interests}

No competing interests to declare.

\section{Author details}

${ }^{1}$ Division of Gynaecology, Department of the Woman, the Child and the Adolescent, Geneva University Hospitals, 30 Bld de la Cluse, 1211 Geneva, Switzerland. ${ }^{2}$ Department of Epidemiology and Public Health, Swiss Tropical and Public Health Institute, Basel, Switzerland. ${ }^{3}$ University of Basel, Basel, Switzerland. ${ }^{4}$ Faculty of Medicine, University of Geneva, Geneva, Switzerland. ${ }^{5} \mathrm{CRC} \&$ Division of clinical-epidemiology, Department of health and community medicine, University of Geneva \& University Hospitals of Geneva, Geneva, Switzerland

Received: 2 December 2020 Accepted: 24 May 2021

Published online: 16 June 2021

\section{References}

1. World Health Organization. Care of women and girls living with female genital mutilation: a clinical handbook. 2018. Available from: https://www. who.int/reproductivehealth/publications/health-care-girls-women-livingwith-FGM/en/. Accessed 18 Jan 2019.

2. UNICEF. Female Genital Mutilation/Cutting: a global concern New York: Unicef; 2016. [Available from: https://www.unicef.org/media/files/FGMC_201 6_brochure_final_UNICEF_SPREAD(2).pdf.] Accessed 8 Apr 2019.

3. World Health Organization. Types of female genital mutilation. 2020. Available from: https://www.who.int/teams/sexual-and-reproductive-health-a nd-research/areas-of-work/female-genital-mutilation/types-of-female-genitalmutilation. Accessed 18 Apr 2020.

4. UNICEF. Female Genital Mutilation/Cutting: a global concern. 2016. Available from: http://www.unicef.org/media/files/FGMC_2016_brochure_final_ UNICEF_SPREAD.pdf. Accessed 18 Jan 2019.

5. Van Baelen L, Ortensi L, Leye E. Estimates of first-generation women and girls with female genital mutilation in the European Union, Norway and Switzerland. Eur J Contracept Reprod Health Care. 2016;21(6):474-82. https://doi.org/10.1080/13625187.2016.1234597.

6. Cottler-Casanova S, Abdulcadir J. Estimating the indirect prevalence of Female genital mutilation/cutting in Switzerland. BMC Public Health. 2021; 21:1011. https://doi.org/10.1186/s12889-021-10875-w.

7. European Institute for Gender Equality. Female genital mutilation. Estimating the number of girls at risk in the European Union: Belgium, Greece, France, Italy, Cyprus and Malta - Report. 2018. Available from: https://eige.europa.eu/publications/estimation-girls-risk-female-genital-mutila tion-european-union-report-0. Accessed 7 Aug 2019.

8. European Institute for Gender Equality. Female genital mutilation. Estimating the number of girls at risk in the European Union: Report. 2015. Available from: https://eige.europa.eu/publications/estimation-girls-risk-fema le-genital-mutilation-european-union-report. Accessed 7 Aug 2019.

9. Ortensi LE, Farina P, Leye E. Female genital mutilation/cutting in Italy: an enhanced estimation for first generation migrant women based on 2016 survey data. BMC Public Health. 2018;18(1):129. https://doi.org/10.1186/s12 889-017-5000-6.

10. Equality Now, City University London. London Institute for Women's health, and FORWARD. Research methodological workshop report: estimating the prevalence of FGM in England and Wales. 2012. Available from: https:// www.equalitynow.org/research_methodological_workshop_report_estima ting_the_prevalence_of_fgm_in_england_and_wales. Accessed 20 Mar 2020 
11. Ortensi LE, Farina $P$, Menonna A. Improving estimates of the prevalence of female genital mutilation/cutting among migrants in Western countries. Demogr Res. 2015;32:543-62. https://doi.org/10.4054/DemRes.2015.32.18.

12. Vogt $\mathrm{S}$, Efferson $\mathrm{C}$, Fehr $\mathrm{E}$. The risk of female genital cutting in Europe: comparing immigrant attitudes toward uncut girls with attitudes in a practicing country. SSM Popul Health. 2017;3:283-93. https://doi.org/10.10 6/j.ssmph.2017.02.002.

13. Cappa C, Van Baelen L, Leye E. The practice of female genital mutilation across the world: data availability and approaches to measurement. Glob Public Health. 2019;14(8):1139-52. https://doi.org/10.1080/17441692.2019.1 571091.

14. Elmusharaf S, Elhadi N, Almroth L. Reliability of self reported form of female genital mutilation and WHO classification: cross sectional study. BMJ. 2006; 333(7559):124. https://doi.org/10.1136/bmj.38873.649074.55

15. Johansen REB, Ziyada MM, Shell-Duncan B, Kaplan AM, Leye E. Health sector involvement in the management of female genital mutilation/cutting in 30 countries. BMC Health Serv Res. 2018;18(1):240. https://doi.org/10.1186/s12 913-018-3033-x.

16. Chou D, Cottler S, Khosla R, Reed GM, Say L. Sexual health in the international classification of diseases (ICD): implications for measurement and beyond. Reprod Health Matters. 2015;23(46):185-92. https://doi.org/10.1 016/j.rhm.2015.11.008.

17. Cottler-Casanova S, Horowicz M, Gieszl S, Johnson-Agbakwu C, Abdulcadir J. Coding female genital mutilation/cutting and its complications using the international classification of diseases: a commentary. BJOG. 2020;127(6): 660-4. https://doi.org/10.1111/1471-0528.16086.

18. Abdulcadir J, Dugerdil A, Boulvain M, Yaron M, Margairaz C, Irion O, et al. Missed opportunities for diagnosis of female genital mutilation. Int J Gynecol Obstet. 2014;125(3):256-60. https://doi.org/10.1016/j.ijgo.2013.11.016.

19. Ali AA. Knowledge and attitudes of female genital mutilation among midwives in eastern Sudan. Reprod Health. 2012;9(1):23. https://doi.org/1 $0.1186 / 1742-4755-9-23$

20. Cappon S, L'Ecluse C, Clays E, Tency I, Leye E. Female genital mutilation: knowledge, attitude and practices of Flemish midwives. Midwifery. 2015; 31(3):e29-35. https://doi.org/10.1016/j.midw.2014.11.012.

21. Turkmani S, Homer C, Varol N, Dawson A. A survey of Australian midwives' knowledge, experience, and training needs in relation to female genital mutilation. Women Birth. 2018;31(1):25-30. https://doi.org/10.1016/j.wombi.2 017.06.009.

22. Tantet C, Aupiais C, Bourdon M, Sorge F, Pages A, Levy D, et al. Female genital mutilation: an evaluation of the knowledge of French general and specialized travel medicine practitioners. J Travel Med. 2018;25(1). https:// doi.org/10.1093/jtm/tax090

23. González-Timoneda A, Ruiz Ros V, González-Timoneda M, Cano SA. Knowledge, attitudes and practices of primary healthcare professionals to female genital mutilation in Valencia, Spain: are we ready for this challenge? BMC Health Serv Res. 2018;18(1):579.

24. Young J, Rodrigues KK, Imam B, Johnson-Agbakwu C. Female Genital Mutilation/Cutting-Pediatric Physician Knowledge, Training, and General Practice Approach. J Immigr Minor Health. 2020;22:668-74. https://doi.org/1 0.1007/s10903-019-00938-X

25. Sureshkumar P, Zurynski Y, Moloney S, Raman S, Varol N, Elliott EJ. Female genital mutilation: survey of paediatricians' knowledge, attitudes and practice. Child Abuse Negl. 2016;55:1-9. https://doi.org/10.1016/j.chiabu.201 6.03.005.

26. Yoder PS, Wang S, Johansen E. Estimates of female genital mutilation/ cutting in 27 African countries and Yemen. Stud Fam Plan. 2013:44(2):189204. https://doi.org/10.1111/j.1728-4465.2013.00352.x.

27. World Health Organization. ICD-10 Training Tool. Structure of the classification and how to code. 2010. Available from: https://icd.who.int/tra ining/icd10training/. Accessed 7 Aug 2019.

28. Abdulcadir J, Catania L, Hindin MJ, Say L, Petignat P, Abdulcadir O. Female genital mutilation: a visual reference and learning tool for health care professionals. Obstet Gynecol. 2016;128(5):958-63. https://doi.org/10.1097/A OG.0000000000001686

29. Abdulcadir J, Alexander S, Dubuc E, Pallitto C, Petignat P, Say L. Female genital mutilation/cutting: sharing data and experiences to accelerate eradication and improve care. Reprod Health. 2017;14(Suppl 1):96.

30. World Health Organization. Female Genital Mutilation Factsheet. c2021. Available from: https://www.who.int/news-room/fact-sheets/detail/femalegenital-mutilation. Accessed 4 May 2021.
31. Gele AA, Kumar B, Hjelde KH, Sundby J. Attitudes toward female circumcision among Somali immigrants in Oslo: a qualitative study. Int J Women's Health. 2012;4:7-17. https://doi.org/10.2147/IJWH.S27577.

32. Mohamed S, Teshome S. Changing attitudes in Finland towards FGM. Forced Migr Rev. 2015;49:87-8.

33. European Institute for Gender Equality. A pilot study for identifying adequate hospital procedures in FGM cases. 2016. Available from: https:// eige.europa.eu/gender-based-violence/good-practices/belgium/registrationfgm-hospitals. Accessed 8 Aug 2019.

34. Alvarez C, Fedock G, Grace KT, Campbell J. Provider screening and counseling for intimate partner violence: a systematic review of practices and influencing factors. Trauma Violence Abuse. 2017;18(5):479-95. https:// doi.org/10.1177/1524838016637080

35. Berg RC, Underland V, Odgaard-Jensen J, Fretheim A, Vist GE. Effects of female genital cutting on physical health outcomes: a systematic review and meta-analysis. BMJ Open. 2014;4(11):e006316. https://doi.org/10.1136/ bmjopen-2014-006316.

36. Chiodini J. Female Genital Mutilation, "vacation cutting" and the travel medicine consultation. Travel Med Infect Dis. 2017;18:87-91.

\section{Publisher's Note}

Springer Nature remains neutral with regard to jurisdictional claims in published maps and institutional affiliations.
Ready to submit your research? Choose BMC and benefit from:

- fast, convenient online submission

- thorough peer review by experienced researchers in your field

- rapid publication on acceptance

- support for research data, including large and complex data types

- gold Open Access which fosters wider collaboration and increased citations

- maximum visibility for your research: over $100 \mathrm{M}$ website views per year

At BMC, research is always in progress.

Learn more biomedcentral.com/submissions 